\title{
Sacral stress fracture in a runner
}

\author{
M. B. Bottomley \\ University Medical Officer, Bath, UK
}

A female 10,000 metre runner, aged 28, presented with a 10 day history of pain of insidious onset in the right buttock. She had, 2 weeks before presenting, competed in a track race for selection to an international representative team, which she achieved. Five days after the race she had a 400 metre interval training session, following which she was conscious of the pain in the right buttock. She continued with her road training, but was aware that her stride was shortened due to the pain which worsened over the subsequent week. She was due to compete internationally some 6 weeks later.

On examination there was a small degree of pelvic tilt, the left side being lower than the right. There was slight compensatory lumbar scoliosis, concave to the right. Clinically, the right leg appeared longer than the left by not more than one half of an inch $(1.25 \mathrm{~cm})$. Movement of the lumbar spine was full and equal in all directions. There was no localized spinal tenderness. Both sacroiliac joints were tender. There was acute and very localized tenderness in the upper, outer quadrant of the right buttock.

No abnormality was found in the hips, other than passive extension of the right hip was slightly limited by comparison with the left. The pain could not be reproduced by passive or resisted movements of the hip.

A plain X-ray of the lumbar spine and pelvis showed no significant abnormality and there was no evidence of erosive change at either sacroiliac joint. A three phase isotope bone scan, 18 days after the reported onset of the pain, showed some early, slight uptake at the lower end of the right sacroiliac joint on the sacral side. The appearances were reported as compatible with a stress related lesion involving the lower medial component of the right sacroiliac joint (Figure 1).

In the view of a consultant rheumatologist, to whom the patient was referred, the lesion was sacroiliac strain, for which an injection of triamcinolone and local anaesthetic was given.

The athlete was recommended not to run and, instead, continued to train in water, using a wet vest. One week after the injection, 4 weeks after the onset of pain, the athlete travelled to a training camp before

Address for correspondence: Dr Malcolm Bottomley, University Medical Officer, Quarry House, North Road, Bath, BA2 7AY, UK (C) 1990 Butterworth-Heinemann Ltd 0306-3674/90/040243-02

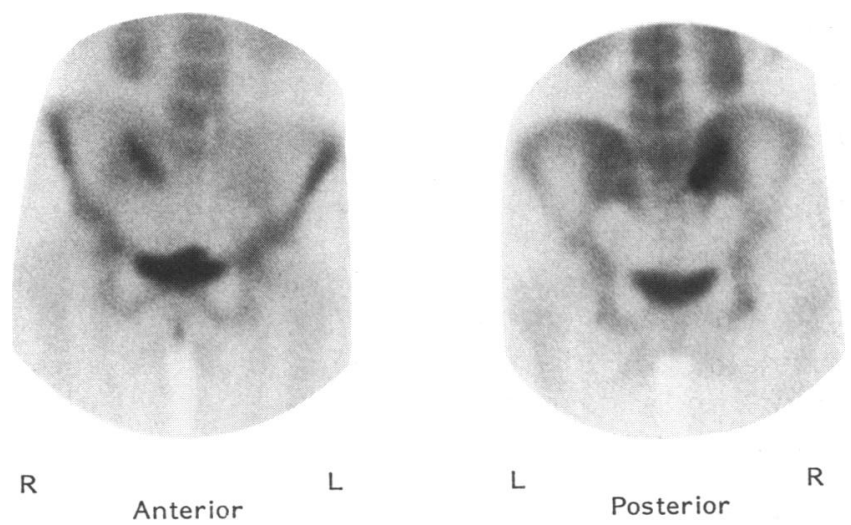

Figure 1. Isotope bone scan showing slight uptake at the lower end of the right sacroiliac joint on the sacral side

international competition. She continued to train in water, with minimal discomfort. Any attempt to run exacerbated the pain. Two weeks later she competed, performing well below her normal standard.

The patient's weight at about the time of the injury was 7 stone $6 \mathrm{lbs}(47.2 \mathrm{Kgs})$, her Quetelet index being 17. Her percentage body fat was 9 . College age females maintain between 20 and $25 \%$ of their body weight as fat ${ }^{1}$. Estimates of bone mineral density were carried out some months after return to the UK. These were taken from the 2nd, 3rd and 4th lumbar vertebrae using CT scanning as the technique. The average bone density was $108 \mathrm{mgm} / \mathrm{cu} . \mathrm{cm}$. The average value in women of the same age is approximately $180-190 \mathrm{mgm} / \mathrm{cu} . \mathrm{cm}$. This is considered to be an effect of the athlete's prolonged amenorrhoea ${ }^{2}$.

Stress fracture of the sacrum is considered to be an unusual injury. A similar fracture was reported in a 26-year-old male runner and was described as unique $^{3}$. In both cases the patients were experienced and highly trained athletes. Each was reported to have leg length discrepancy, which may be considered to be a significant factor in the causation of their problem. Whilst the majority of anatomical variations are unimportant for normal living purposes, they become important at higher levels of activity. Leg length differences lead to unequal stride length and corresponding asymmetrical movements of hips, sacroiliac structures and the lower spine ${ }^{4}$.

It seems reasonable to assume that, in each case, there was some event that led to decompensation of 
their biomechanical inequality and, in the case of the athlete described above, this may well have been muscular fatigue consequent upon an extremely hard training session a few days after an equally hard race. In addition, the low bone density is likely to be a contributory factor.

This injury was discovered by chance. Many athletic injuries are unfamiliar in the general population. The fact that they are described as unique or unusual may well be a reflection of our lack of knowledge, which carries with it the risks of under investigation and inappropriate treatment.

\section{Acknowledgements}

I am grateful to Dr Malcolm Read for his continuing persistence in ensuring that this case was reported and to Drs Roger Wolman and Mark Harries, both of the British Olympic Medical Centre, for supplying the information on bone densities which forms part of their own ongoing study.

\section{References}

1 Drinkwater, B. Training of female athletes. Olympic Book of Sports Medicine, Blackwell, 1988

2 Wolman, R.L. Personal communication

3 Czarnecki, J., Till, W. and Minikel, J.L. Unique sacral stress fracture in a runner $A J R$ 1988, 151, 1255

4 Sperryn, P.N. Sport and Medicine Butterworth, 1983 